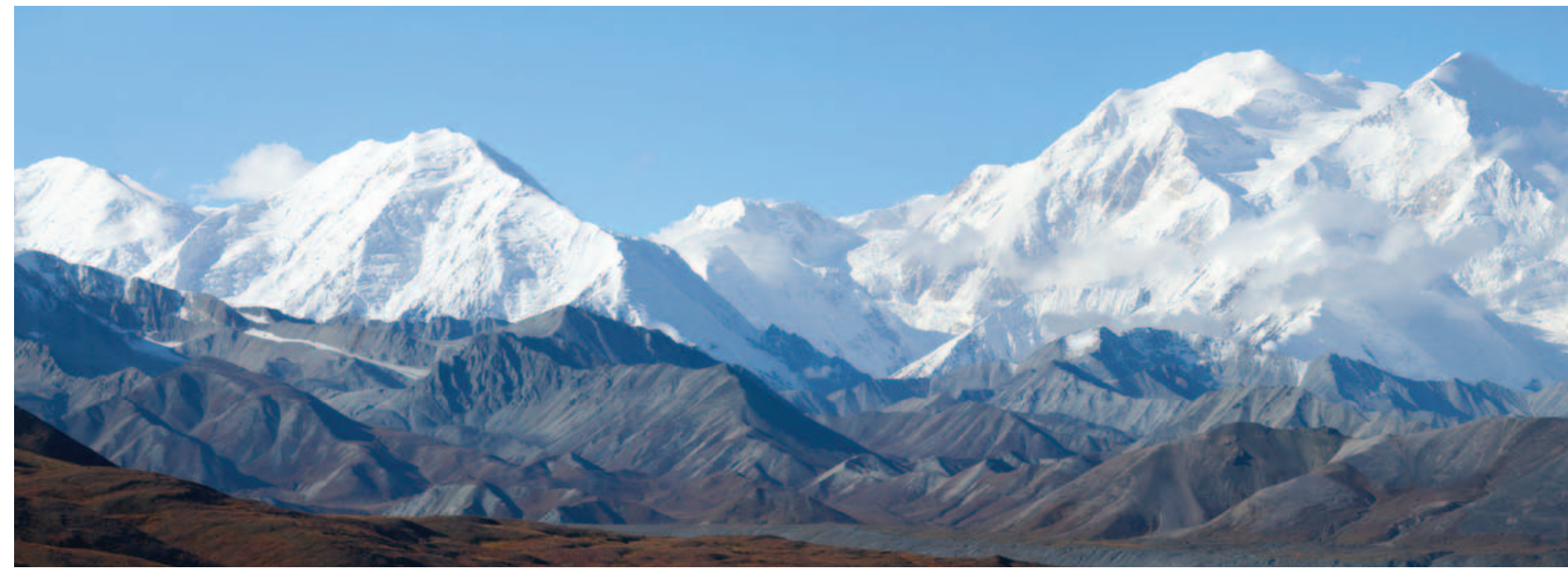

\section{Empowering Indian Country to Energize Future Generations}

The on-the-ground START program is part of a broader DOE-IE effort to make reliable, accurate technical information and skills-based training available to tribal communities throughout the United States. Ultimately, these efforts will serve to further the Administration and DOE's shared commitment to provide Native American and Alaska Native communities with the tools and resources they need to foster tribal energy self-sufficiency and sustainability, advancing job creation, and enhancing economic competitiveness.

The DOE Office of Indian Energy Policy and Programs is charged by Congress to direct, foster, coordinate, and implement energy planning, education, management, and programs that assist Tribes with energy development, capacity building, energy infrastructure, energy costs, and electrification of Indian lands and homes.

\section{Advancing Next-Generation Energy in Indian Country}

\section{What is START?}

The Strategic Technical Assistance Response Team (START) Program is a U.S. Department of Energy Office of Indian Energy Policy and Programs (DOE-IE) initiative to provide technical expertise to support the development of next-generation energy projects in Indian Country.

The START Program seeks to spur clean energy project development by providing Tribes with tools and resources needed to foster energy self-sufficiency, sustainability, and economic competitiveness. With the support of technical experts from the National Renewable Energy Laboratory (NREL), START assists tribal leadership with project development and financing and helps tribal communities strategically plan their energy future.

\section{What does START do?}

Emphasizing long-term and meaningful impact in Indian Country, START addresses a variety of renewable energy technologies, as well as the diverse spectrum of tribal communities across the United States. START project and community-based assistance is delivered to federally recognized Native American and Alaska Native governments through two distinct START initiatives. The first centers on clean energy project development support for specific Tribes in the contiguous 48 states. The second initiative focuses on community-wide energy planning, workforce training, and project support for Alaska Native communities.

\section{Where is START?}

START-supported projects and communities were selected through a competitive application process. Between December 2, 2011, and January 15, 2012, 46 American Indian and Alaska Native Tribes submitted applications to receive on-the-ground technical support through START. Technical assistance activities are scheduled for summer and fall 2012. 


\section{START Program: Alaska}

Alaska Native governments will be paired with DOE, NREL, and other Alaska-based experts who have clean energy deployment experience relevant to the Tribe's project development stage and technology. The selected communities will receive assistance with conducting community-based planning and training and implementing a variety of clean energy projects, including energy storage infrastructure, renewable energy deployment, and housing energy efficiency.

Alaska START technical assistance will be bolstered by DOE-IE's partnership with the Denali Commission, an independent federal agency designed to provide critical utilities, infrastructure, and economic support throughout Alaska that will provide additional assistance and expertise, as well as $\$ 300,000$ in funding to fuel the START initiative.

The following Alaska Native communities applied for and were selected to receive START technical assistance from DOE-IE.

- Arctic Village Council will receive assistance with optimizing the community's powerhouse generators, supporting Power Cost Equalization (PCE) reinstatement, installing pre-pay meters for residential buildings, and exploring feasibility of community-scale solar energy generation.

- Native Village of Kwinhagak/ Quinhagak will receive assistance with developing a community energy plan, increasing residential energy efficiency, implementing a heat recovery project, producing a wind-to-heat report, and preparing the village to pursue additional funding opportunities.

- Native Village of Teller will receive assistance to address long-term bulk fuel storage capacity needs; identify opportunities to increase residential energy efficiency, including education and training; implement retrofits and repairs for public facilities; and prepare for additional funding opportunities.

- Organized Village of Kake will receive assistance with developing a community energy plan, relocating a wind met-tower closer to the village, conducting biomass and hydro generation feasibility studies, identifying bulk diesel improvements, and initiating residential energy efficiency activities.

- Venetie Village Council will receive assistance with developing a community energy plan, repairing public utility generation infrastructure, supporting PCE reinstatement, developing a utility rate structure, installing solar photovoltaic monitoring equipment, and conducting a biomass feasibility study with project design review.
"Tribal communities, entrepreneurs, and small businesses will benefit greatly from the technical resources and expertise provided by DOE. START will help Native American and Alaska Native communities increase local generation capacity, enhance energy efficiency and conservation measures, and create job opportunities in the new clean energy economy."

-Director Tracey A. LeBeau DOE Office of Indian Energy
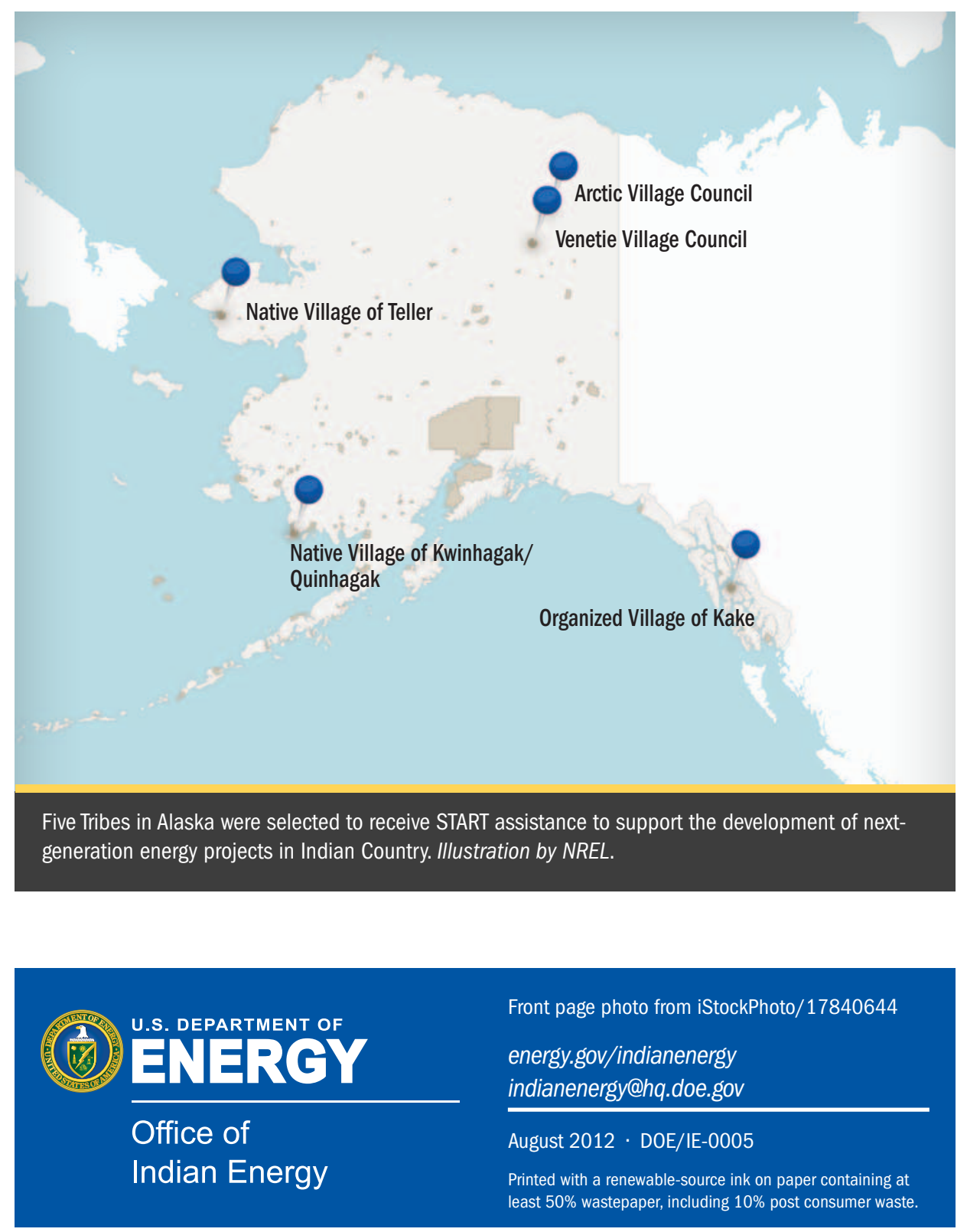